\title{
The lurch towards formalisation: Lessons from the implementation of BRT in Johannesburg, South Africa
}

\author{
Christoffel Venter \\ Centre of Transport Development, Department of Civil Engineering, University of Pretoria, Pretoria, South Africa, \\ +27-12-4202184, christo.venter@up.ac.za \\ Keywords: \\ Bus rapid transit \\ Informal public transport \\ Minibus taxis \\ South Africa \\ Life cycle analysis \\ Formalisation
}

\section{ABSTRACT}

The City of Johannesburg, South Africa, implemented the first phase of its Bus Rapid Transit (BRT) system named Rea Vaya between 2009 and 2011. The system design and organisational arrangements drew heavily on precedents from South America, especially insofar as BRT is used as an instrument for securing the transformation and formalisation of a fragmented and problematic informal public transport industry. Despite the inevitable transition problems, the formalisation scheme appears to be generally successful - an outcome that surprised many analysts as it follows a long history of mistrust, resistance, and unsuccessful interventions between government and the minibus taxi industry. The paper offers an analysis of the reasons for the successful transformation of participating taxi operators, by using a life-cycle analogy. We argue that the minibus-taxi industry in South Africa has reached a state of stasis and maturity, with limited opportunities for further growth in its present form. BRT, as it is implemented locally, offers opportunities for re-invention for moving onto new a potential growth trajectory - by overcoming the binding constraints of informality and by opening up new markets to operators. The life-cycle analysis also offers some insights into critical success factors that, if not met in the long run, could jeopardize the longevity and scalability of the formalisation project. The paper concludes with insights regarding the planning and management of BRT systems to maximize their potential for leveraging the formalisation of informal operators, both in South Africa and in other developing countries.

\section{Introduction}

Informal providers of public transport are a significant part of the transport landscape in many developing countries. Informal transit is typically defined as services provided by small private operators substantially outside of the ambit of government regulation, and typically employing small vehicles (Gwilliam, 2006). While informal operators have been argued to offer advantages to users, notably in terms of low fares and high availability (Gwilliam, 2006), many analysts also point to their negative impacts - including predatory pricing, low vehicle and passenger convenience standards, poor road safety records, and significant contributions to environmental and congestion externalities (Gwilliam, 2006; Gilbert, 2008; 
Walters, 2008) as justifications for greater government involvement in and regulation of their operations. As a result, informal public transport has historically been regarded as "a problem to be solved" by government, official attitudes towards informal operators ranging from passive toleration to outright hostility. At the same time limitations inherent to the informal business model have prevented significant improvement to emerge from within the industry itself. Accounts of the variety of methods that have been devised to try to bring operators within the fold of government's administrative, planning, and financial regulatory mechanisms - ranging from the revamping of licensing and regulatory regimes (e.g. Hook, 2005; Finn et al. 2009) to commercial contracting (Hidalgo, 2009) to forced fleet renewal (DOT, 2006) highlight the difficulty of achieving success, due to a combination of limited implementation capacity, and active resistance from the informal industry itself (Oosthuizen and Mhlambi, 2002; Schalekamp et al. 2009).

An approach that seems to have offered attractive opportunities for facilitating the transformation of informal operators into formal sector participants, is to use new Bus Rapid Transit (BRT) systems to simultaneously leverage the innovation of both the technical and business sides of public transport. The most famous example of this approach is the concession model adopted by the TransMilenio system in Bogotá, Colombia, by which incumbent informal bus operators were incorporated into formal operating companies contracted to provide trunk and feeder route service under contract to the BRT authority (Hook, 2005). The TransMilenio model appears to be popular among analysts and planners in developing countries. Yet recent analyses highlight the difficulties of sustaining BRT-driven processes of paratransit integration, especially when all informal operators are not included in the formalisation process and difficult issues of managing "parallel" informal services are raised (Gilbert, 2008; Schalekamp et al. 2009).

This paper offers a review of recent experience in South Africa with the implementation of Bus Rapid Transit, and specifically its use as a transformational mechanism for moving a fragmented and largely reluctant informal industry towards formal participation in BRT. The paper aims, by tracing the trajectory of informal operators' resistance to and eventual embrace of formalisation, to offer insights into the opportunities presented by BRT for facilitating formalisation in the developing country context; and to examine the conditions under which such a transformation can be sustained.

The paper firstly attempts to put the transformation of the minibus-taxi industry in its historical context, providing a brief overview of previous failed attempts at state intervention. It then offers an outline of the conditions typical of informal operations, arguing that informality becomes a trap from which individual operators have neither the desire nor the means to escape on their own. The point of departure is that the informal industry needs to be understood for what it is, before attempts are made to reform or transform it. As a case study of the opportunities offered by the BRT service model for escaping the logic of informality, the experience in the City of Johannesburg, where the country's (and the continent's) first fully fledged BRT service has been launched, is recounted. In an attempt to explain what can be seen as an unexpected lurch by sections of the taxi industry towards formal participation in the BRT, we utilize a life cycle analogy, arguing that the informal public transport industry is facing stagnant technological and market realities, from which BRT (and other bus enhancement schemes) might offer escape. The life cycle analogy also provides insight into the success factors for BRT if it is to remain successful as a means of leveraging the formalisation of informal operators, both in Africa and in other developing countries. 
The source material for this paper includes literature and media articles published on the Rea Vaya system between April 2009 and July 2011, as well as interviews with industry and government role-players.

\section{Background: A history of failed state intervention in the minibus taxi industry}

While it is not the intention here to provide a complete overview of the emergence of the informal public transport industry in South Africa (for more complete accounts see McCaul, 1990; Khosa, 1991; Dugard, 2001), it is instructive to consider key aspects of its history, particularly focusing on the vacillating attitudes of the government towards the industry.

\subsection{Genesis, deregulation, and explosive growth}

The informal public transport industry emerged in the 1970s as an entrepreneurial response to the inadequacy of state-subsidised bus and commuter rail services within urban townships (black residential areas) of South Africa. Initially operated with sedan vehicles (especially Valiants and Chevrolets), the mode was not seen by Apartheid officials as a significant part of the transport system, to the extent that privately operated minibuses with a capacity of up to 8 passengers were allowed to enter the public transport market in selected area where they would not compete with formal services. By 1982 the new White Paper on National Transport Policy allowed 16-seater minibuses to operate legally.

Similar to the experience with informal transport services elsewhere in Africa, the minibus taxi mode grew fast in popularity due to its superior convenience, speed, and frequency as compared to formal bus and rail alternatives. Private-sector operators of subsidised bus services, becoming increasingly concerned about the competition offered by the minibus, canvassed government to phase out the nascent industry. However internationally the policy pendulum was already swinging in the direction of economic liberalisation; in South Africa this lead to a decision to completely deregulate entry and exit to the public transport market. The Transportation Deregulation Act of 1988 removed most entry barriers to minibus services. While local government structures could limit the number of permits based on criteria like availability of rank space, this rarely happened in practice. This constituted the first official recognition of the taxi industry as a part of public transport in South Africa, albeit under a weak regulatory regime.

Three important consequences followed the deregulation of taxi transport. Firstly, the minibus taxi mode experienced explosive growth between 1987 and 1994. Khosa (1991) reports that in just one year, 1986-87, the number of permits issued nationwide rose from 7,093 to 34,378 . Several explanations have been offered for this growth, all of which are relevant to the shaping of the subsequent formalisation debate. Apart from the attractiveness of the service, which by its very informal nature was quick to respond to commuter needs, penetrating more deeply into residential areas than either bus or rail alternatives (Boudreaux, 2006), the taxi industry also gained popularity as a community resistance response to the power of the apartheid state, surviving (and thriving) in a space where challenge to state authority was normally not allowed. The informal taxi industry also became one of the first avenues for capital accumulation among black persons, whose participation in the formal economy was largely restricted. Even today, free market proponents describe the taxi 
industry using terms like "a miracle of invention" (Cohen, 2009) and "a showcase of black capitalism" (Fourie, 2003:17).

The industry thus almost immediately became contested economic terrain (Fourie, 2003), flooded by aspirant owners. Vicious competition between operators ensued, leading directly to the second important consequence of deregulated competition: the emergence of voluntary operators' associations. In the absence of any formal mechanisms for allocating routes between operators, area-based associations started to claim ownership over routes and rank space, and wielded great control over access to routes or the addition of vehicles to these routes (Ahmed, 2004). Individual taxi owners paid a hefty fee for joining an association, in exchange for the right to operate. The foremost task of voluntary associations was thus the protection of property rights, rather than representing or promoting the interests of its members in any general sense by participating in any formal governance structures or industry bodies.

Because arrangements in the taxi industry were not enforced by the police, these "property" rights were enforced privately, by the associations, who would send "squad" cars out to patrol their areas (Boudreaux, 2006). Thus emerged the third important consequence of deregulation: the use of violence and threats of violence to settle disputes and enforce informal property rights. Deaths and injuries from taxi violence climbed throughout the 1980s, reaching a high of 330 deaths in 1993 (Dugard, 2001). This situation contributed to a popular perception of the industry as illegal, operating with impunity outside government's law and order structures and societal norms. After studying taxi violence in South Africa, Dugard (2001) concluded that "the continuation of violence into the democratic era was mainly a result of the success of violence as a means of extracting profits" - implying that violence became an unofficial element of the taxi industry's business strategy.

Severe competition exerted pressure on vehicle and driver standards, reflected most notably in a drop in road safety. For instance, it was reported that in 1998 taxis constituted about 2$3 \%$ of vehicles on SA roads, but were involved in a quarter of road accident fatalities (Fourie, 2003:48).

In summary, the minibus taxi industry entered the era of democratic governance in South Africa with a contradictory history of innovative, effective entrepreneurship and strong community credentials, offset by a culture of severe internal mistrust and poor cooperation with external role-players. This set the stage for continuing problems in later years.

\subsection{Transformation attempts in the democratic era}

The size and importance of the minibus-taxi industry as a mobility provider grew to such an extent that it soon became the foremost public transport mode in South Africa. In 2003, 60 percent of commuters used minibus taxis (DOT, 2003), with the number of vehicles nationally estimated at 130,000 .

From 1995 onwards the new South African government, acting on a new understanding of the importance of the taxi industry, started engaging with industry more seriously. A National Taxi Task Team set up by the government recommended state regulation and formalisation of the industry as a matter of urgency, noting that the deregulated operating environment was the cause of many of the illnesses endemic to the industry. Formalisation was meant to 
be comprehensive, covering the key areas of administrative, financial, and industrial formalisation, as follows:

- Administrative formalisation, or legalisation, involved the registration of existing operators (including those operating without permits), in order for government to start the planning and regulation process. In an effort to address the oversupply of taxi transport, a moratorium was declared on the issuing of permits. However, this did little to check further growth as new entrants simply continued to operate without permits.

The National Land Transport Transition Act, enacted in 2003, directed government to rationalize public transport, decrease destructive competition between modes, and progressively move towards an integrated system under overall government authority. While this was in principle in line with a movement internationally of allocating to government strong planning and quality assurance roles, but letting private sector provide transport services (Barter, 2008), it was adopted without engaging incumbent taxi operators to whom it was quite clear that the role of small vehicles in such a rationalized system would be a much reduced one restricted mostly to feeder and low-density line-haul routes. Thus it can be argued that the minibus-taxi sector never bought into government's vision for a more efficient transport system.

- Financial formalisation, or recapitalisation: Realising that taxi owners faced a problem typical of informal industries in its inability to reinvest in its own fleet, government instituted a bold programme of recapitalizing the entire national taxi fleet. The main aim of the Taxi Recapitalisation Programme was to assist and force industry to replace the existing fleet of 16-seater minibuses with newer, larger, and purpose-designed 18 to 35 seat vehicles. The intention was to simultaneously reduce the oversupply of vehicles (estimated at some 60,000 vehicles), and to improve safety and passenger accessibility standards. The incentive was a scrapping allowance of R50,000 (now R55 000) paid to participating owners, at a total cost to the fiscus of at least R7,7 billion (Venter, 2010).

Hailed as a "massive revamp" of the taxi industry (Fourie, 2003), the recapitalisation programme stands out as the first attempt by the South African state to direct large-scale financial assistance to the taxi industry. A prerequisite to receiving funding was financial formalisation, in the form of registering for taxation, which also implied the need to moving towards formal financial accounting practices.

The recapitalisation programme has achieved some success in terms of upgrading taxi fleets in more lucrative markets: in 2011 about 44,000 old vehicles were scrapped (RSA, 2012). However the cumulative total is below expectations. The programme continues to be criticized as being likely to cost jobs, raise fares, and to create a demand for "illegal" informal services with lower fares by raising entry barriers (Boudreaux, 2006). 
- Industrial relations formalisation, or democratisation: In an attempt to establish a single representative industry body with whom it could negotiate and consult, government pushed for the founding of a national Taxi Council (SANTACO). However factionalism and competitive pressure within the industry inhibited the emergence of a truly representative voice (Fourie, 2003); despite the fact that government consults with SANTACO on issues of national concern, a number of fragmented bodies speak for regional constituencies, each either supporting or opposing the taxi recapitalisation scheme depending on their commercial interests.

The South African government's efforts at moving the minibus-taxi industry towards formalisation over the last decade and a half has been characterized, firstly, by the channelling of significant amounts of state resources towards the industry. This, in itself, reflects a serious attempt at engagement and a break with the state's past adversarial or neglectful stance. A second characteristic of the era is that most efforts fit into a top-down mould, with government designing and planning various transformation programmes and transport plans that would in most cases amount to significant reorientation of the taxi business, without allowing sufficient opportunity for engagement and participation by the industry itself. This top-down approach, as will be shown below, takes insufficient account of the inherent limitations of the informal mode of operation.

\section{Locked into the logic of informality}

The failure of government to move the taxi industry towards formal participation in the public transport market can only be explained by a careful analysis of the business and operating conditions under which it operates as an informal industry. Portes et al. (1989) suggest that informal business practices are driven in large part by the desire to reduce costs by escaping the labour rules and unionisation applying to formal entities. This is especially feasible in developing countries with weak regulatory regimes and low employment levels. In the South African taxi industry there is indeed evidence of what the International Labour Organisation calls "highly exploitative labour practices" (Barret, 2003:ix), despite recent attempts to regulate minimum wages and employment conditions through labour legislation.

Despite its attractiveness as a competitiveness-enhancing strategy, informality inherently imposes limitations on a business that are seemingly difficult to overcome. The most important limitations relevant to this discussion relate to capital availability, possibilities for cooperation, and human resource development.

- Capital: Without formal financial accounting and savings mechanisms, or adequate access to finance and credit, informal businesses often lack working capital with which to finance expansion. Thus Paul Browning, long-time observer of the taxi industry, concludes that "if wealth is taken to mean the formation, retention and appreciation of capital at a rate greater than that of inflation - then the taxi industry has significantly failed" (Browning, 2001).

- Cooperation: Fierce independence, mistrust, and extremely decentralized decision making (with individual drivers often capable of deciding which routes to operate on any given day) characterize the taxi industry. The fear of losing control 
or giving up any competitive advantage they may have prevents individual operators from merging into larger, more efficient units, where more capital could be mobilized. Voluntary associations serve the purpose of protecting and allocating revenue rights, and occasionally facilitates cost-reducing cooperation amongst its members (for instance through bulk purchases of fuel or spare parts), but do not seem to be very successful at promoting commercial innovation and scaling.

- Human resource development: Small operating units combined with a lack of training and skills development prevents the professionalisation of taxi businesses, where the management of operations - vehicles, drivers and terminal activities - can be improved by employing appropriate management principles (Browning, 2001).

The limitations of informality described above create conditions under which it is very difficult to grow, except through duplication of a standard service for as long as demand exists for this service. Growth that requires risk taking and innovation rarely occurs, as small operating units do not have the margin to recover from failure. Fragmentation prevents the emergence of sufficiently representative bodies to enlist government help in constructive ways. The very logic that makes informality attractive at first becomes a trap from which it is difficult to escape.

\section{Bus Rapid Transit: A new chance for transformation? The case of Johannesburg}

In March 2007 the South African cabinet approved a public transport strategy that was the first coordinated attempt to upgrade public transport in an integrated manner (DOT, 2007). Most importantly, it allocated significant funds for infrastructure and vehicles for this purpose. With funding in hand, the City of Johannesburg as the largest city in the country embarked on the design and construction of South Africa's first Bus Rapid Transit system, named Rea Vaya or "We are going", as a means of incrementally addressing both severe traffic congestion and persistent mobility problems of the 1.5 million-strong population of public transport users in the city. The first corridor, consisting of a 25 kilometer trunk line with median lanes, 27 trunk stations, and feeder routes, connects the Central Business District and Soweto. It runs along one of the busiest commuter corridors in the city.

Building on the experiences of BRT systems in Colombia, the planners of Rea Vaya intended to allow the local minibus taxi industry to play a major role in its operation, seeing it as an opportunity to facilitate their transformation into formal operators while improving the overall quality of public transport. Thus in 2007 the city embarked on a process of consultation, study tours, and negotiation with taxi industry leaders (see McCaul and Ntuli (2011) for an exhaustive description of the negotiation process and agreements). Given the history of failed state intervention and mistrust between the two parties, it was by no means clear that the process would end favourably. Would the BRT project at last provide the right combination of incentives and support to allow taxi operators to make the leap to formalisation? 
The city started to engage with representatives of 18 taxi associations potentially affected by Phase 1 of the Rea Vaya, incrementally securing trust between the parties. A cautious memorandum of agreement was signed in October 2007 during which the two taxi umbrella bodies (the Regional Taxi Council and the Top Six Taxi Management) pledged to be "actively and positively involved" in negotiations, even while withholding its full support until details were clearer (COJ, 2007). Their stature grew through formal engagement with the city via a joint Steering Committee, up to the point where the representatives were willing to identify themselves publicly as a "Taxi Industry Negotiation Team" mandated by their respective associations to work towards full participation in the project.

Regarding the replacement of affected taxi routes with BRT, the city's intention was clear from the beginning: existing operators would withdraw their vehicles from competing routes and in exchange become operators of the new system. Disagreement with and uncertainty around the implications of this stance caused considerable discord among the taxi industry's rank and file - although mostly from sectors of the industry not directly affected by Phase 1 , and therefore excluded from the negotiations process. The months before the system launch were characterized by threats of mass action and violence. Roads were blocked by demonstrating taxi drivers. Announcing that they feared the "BRT will not only take food from [my] table but will snatch it from my mouth" (Dibetle, 2009), taxi operators revealed the depth of their distrust of the process. The city (backed by national government) declared that the BRT would be implemented in such a way that no legitimate jobs would be lost; yet, reflecting their previous experience with government schemes involving taxi operators, incumbent operators seemed unwilling to believe such promises.

Four days before the launch of Phase 1a of Rea Vaya, scheduled for 31 August 2009, an urgent (but unsuccessful) court application was made by a taxi grouping called the "United Taxi Association Forum" to stop the launch, on the basis that it contravened an earlier undertaking of government to finish negotiating with everybody before running a single BRT bus. The national taxi body, Santaco, threatened to embark on national strike action in protest at being left out of the local negotiation process. The threat of violence was real; uncertainty was high.

As it turned out, these protestations were the convulsions of an industry facing a painful metamorphosis. On 31 August, the first buses departed from the bus depot, driven by bus drivers who until a few weeks before had been behind the wheel of a minibus. No formal agreement was in place yet, but individual taxi drivers had been signing up with the city for training and deployment via a temporary bus operating company. As passenger numbers grew and operational hitches ironed out, it became clear that the BRT system was, by hook or by crook, working (COJ, 2009).

Three days after opening, violence erupted. Gunmen opened fire on a nighttime BRT bus in Soweto, injuring two passengers (one of whom was an on-board policeman). The security forces responded with a massive raid and widely publicized manhunt. For months afterwards buses and stations continued to be guarded by police and army personnel.

Negotiations between taxi representatives and city authorities continued for another 14 months, during which a number of agreements were hammered out regarding issues such the identification of affected operators, formation of a Bus Operating Company, the basis of shareholding, employment of displaced taxi drivers, and, of course, compensation (McCaul 
and Ntuli, 2011). A contract was finally signed on 28 September 2010, in terms of which 313 taxi operators gave up their businesses and became co-owners (and, some, employees) of a new operating company with a 12 year contract for running trunk and feeder route services for Rea Vaya. Each operator agreed to scrap their taxi vehicle(s) under government's recapitalisation programme, and to invest the scrapping allowance in the new company as working capital. The company would be compensated on a per-kilometer basis, and operators entitled to additional compensation in early years to secure them monthly incomes that would be commensurate with their previous incomes from running taxis. The city, in essence, assumed all demand risk.

\section{Analysis of a turnaround: how do we explain the lurch towards formalisation?}

The agreement of sections of the Johannesburg taxi industry to abandon its conventional informal business model, long developed and jealously guarded, to enter the arena of formalised, contracted public transport operations in partnership with the state, can be seen as a significant lurch towards formalisation. To taxi industry role-players, it represents a decisive departure from historic patterns of (non)-engagement and resistance to change. To the state, it represents a critical step towards removing risks to its strategic programme of upgrading public transport nationwide. Since Johannesburg, taxi groups in other cities have declared themselves in favour of BRT, stating that they intend to "transition into the new integrated public transport service" (Prinsloo, 2011). How do we explain this apparent turnaround in the ranks of the taxi industry?

The events in Johannesburg can be given two possible readings:

1. Formalisation of the taxi industry can be seen as a story of successful government intervention, where a relatively weak industry is forced through strong regulation and engagement to adopt new operating models more in line with state objectives.

2. Alternatively, formalisation can be seen as the ultimate outcome of internal reinvention driven by self-interest, as a bottom-up response to a stagnant technological-economic reality and an alternative offered by the state that was both attractive and feasible.

While the truth probably contains elements of both explanations, it probably leans more towards the second than the first. The history of the minibus-taxi industry in South Africa, and especially the failure of many government-driven schemes to formalize and transform it from the outside, suggest the limitations and ultimate failure of the top-down approach. It has been argued already that the informal business model creates conditions from which it is difficult to effect an unaided escape, as both the strategic vision and the means to change are absent. Government's difficulty in enforcing its rules regarding quantity and quality regulation in the public transport industry has failed to create a strong enough force to push operators towards formalisation. Some operators resist what has been called "a grand effort at state intervention" (Cohen, 2009) in principle, on the basis of their rejection of the right of government to interfere in what is thought of as a private-sector business undertaking. 


\subsection{The systems evolution explanation}

The second explanation casts the story of transformation as one of enlightened self-interest, coupled with timely and appropriate opportunities and incentives offered by government to allow the limitations of informality to be overcome. A useful metaphor to help explain this is that of the life cycle of systems. Several authors have noted that technological systems, including transportation systems, move through successive periods of birth and development, growth and expansion, and saturation and maturity (e.g. Grübler, 1990; Perkins et al. 2005). Extent of deployment plotted against time describes an S-curve, with the full growth cycle of transportation systems typically spanning about 60 to 70 years.

The minibus-taxi mode in South Africa, in its current informal mode of ownership and operation, is clearly in the mature phase of its life cycle. Figure 1 plots the estimated size of the national fleet over time, revealing an S-curve with presently stagnating vehicle numbers. While tight state control limited the expansion of the mode for the first 20 years, the period of fast growth and expansion corresponds to the post-deregulation period of the 1990s. It is also in this period where the formation of hard technologies - such as the standardisation of the 16-seater vehicle design - and soft technologies - such as the establishment of taxi associations - occurred. By 2010, the available markets for taxi transport are essentially saturated. The share of commuter traffic carried by taxis has remained static at around $65 \%$ for the past decade (DOT, 2003; DBSA, 2006), and expansion occurs mainly at the edges of cities where new (mostly informal) settlements are established. The mode of expansion is simply duplication of a standardized product - severe competition and tight profit margins preclude innovation within the industry - and this is a typical characteristic of mature technological systems.

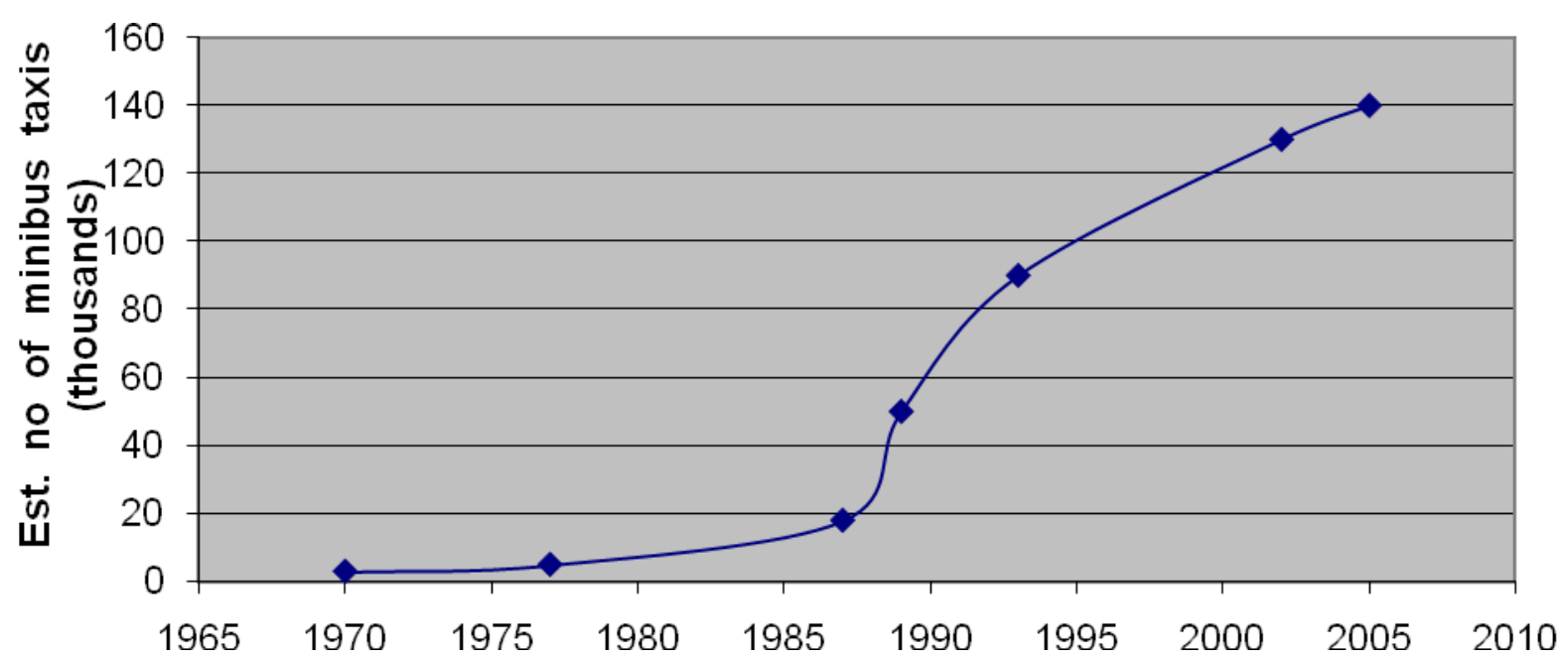

Figure 1. Estimated number of minibus-taxis nationally, 1970 to 2006. (Various sources)

What is needed for a mature industry to break the logic of system evolution, to enter a new S-curve with new growth and profit possibilities, is, according to Garrison and Levinson (2006), to combine scale economies with quality-enhancing "new" technologies. Scale economies imply obtaining access to new markets, more customers, who might in turn be 
attracted by the enhanced quality of the service. Quality enhancement, in turn, can only be paid for by spreading costs out over larger markets.

Some leaders in the taxi industry are acutely aware of the limited opportunities for natural growth. Rustenburg taxi leader Herman Sebego sees transformation as a "logical evolution for the industry moving forward" (Prinsloo, 2011). What the advent of Bus Rapid Transit is offering the industry seems to be a chance to negotiate an emergence from the informal market, while relying on state help to overcome some of its critical limitations. In particular, the BRT concept as it is being structured in Johannesburg offers the following critical opportunities:

- BRT offers the chance to employ a "quality-enhancing new technology", which could both drive down (operating) costs and attract new customers. Like other technological advances, the newness consists of the way in which advantageous practices that are already in existence are combined to produce a new product (Garrison and Levinson, 2006). In the case of BRT, the advantageous practices include longitudinal separation of bus lanes, and the use of closed stations and pre-boarding fare collection - both of which are concepts long in use in passenger rail systems - that can raise the operating speed of BRT significantly above that of modes operating in mixed traffic. Increased speed, together with the use of larger vehicles, can result in lower unit costs due to a reduction in fuel consumption and labour costs - both major components of variable costs - and an increase in the number of round trips per vehicle per day.

- The superior performance of BRT might expand the market for public transport services, thus enhancing the scale economies desirable in a new service. Some marginal amount of additional travel might come from increased mobility by existing public transport passengers, although this is likely to be limited by affordability constraints. The major impact would however come from attracting former car users, attracted by the savings in travel time and perhaps parking cost.

- The Rea Vaya model in Johannesburg is also structured to neutralize the most binding constraints faced by present taxi industry role-players. The lack of working capital is overcome by mobilising state funds to provide infrastructure (including bus lanes, stations, control centres, and even depots to be leased to operating units), and to purchase bus fleets (to be leased to operators and paid back over time). Participating operators are required only to invest whatever assets they currently possess: old taxi vehicles to be traded in for the taxi recapitalisation programme's scrapping allowance, as well as the right to operate on routes parallel to the BRT line.

- Formal contracting, and the formation of formal operating companies owned by former taxi operators, are designed to overcome the resistance among operators to cooperate with each other. Commercial risk is carried entirely by the city: BRT operators are paid a fee per bus-kilometre, regardless of passenger numbers. The city also assists with training and professionalisation of the work force, thus helping to overcome human capital development constraints. The very process of negotiating with city authorities builds relationships of trust within the industry, between former adversaries (Motshwane, 2011). To taxi industry participants, the overall impact of the 
negotiated approach is to greatly reduce the risks and uncertainties of mutual cooperation.

\section{2 "Magic bullet" requirements for sustainable transformation}

The combination of expanded scale economies with technological advances has been termed the "magic bullet", as it seems to be among the best ways of improving systems that are facing maturity and decline. But, as Garrison and Levinson (2006) point out, magic bullet proposals are very risky: to make a difference that is more than marginal, significant capital must be invested. This suggests that, in the case of BRT, some key conditions need to be in place if the successful participation of formerly informal taxi operators is to be sustained and expanded.

- Condition 1: Ability to drive down costs by capturing economies of scale. It seems clear that, in contrast to earlier promises of BRT's potential for subsidy-free operations, BRT in South Africa is substantially more expensive than originally thought. Rea Vaya officials estimate fare revenue to be enough to cover variable operating costs, but not all fleet costs. In addition, the city is paying a substantial "transformation premium" in the form of loss of income compensation and restraint of trade payments, which proved necessary to make participation in Rea Vaya sufficiently attractive for affected taxi operators to abandon their taxi routes. Without subsidy, BRT does not offer the same opportunities for immediate profits as does the informal taxi industry with its tax-avoiding, labour-exploiting, low-cost business model. This makes the BRT system's long-term sustainability dependent on the allocation of substantial subsidy, which is a precarious situation given the parlous state of municipal finances and central government's reluctance to take on more recurrent financial burdens. The City can thus be expected, in the long run, to shift more commercial risk onto the operator, which will put it under increasing pressure to improve its own operating efficiency in order to realise savings and reduce subsidy dependence.

- Condition 2: Ability to expand markets. This depends largely on BRT's ability to provide attractive enough alternatives to current and potential car users. Achieving this demands skill at protecting service quality levels over time - a difficult challenge since quality easily deteriorates as volumes increase and equipment ages, as is the case in Bogota's Transmilenio (Gilbert, 2008). Ongoing traffic management and law enforcement effectiveness are needed to protect the speed advantage offered by the use of dedicated lanes. Even more important is the political will required to expand service into areas with higher proportions of car users experiencing high congestion, especially if BRT lanes are poached from the car. Whether this can be achieved given the relative strength of the car lobbies is an open question (and critical risk factor) that has not been tested in South Africa. Without such expansion, it is not clear that sufficiently new markets can be captured to make it attractive enough to increase the number of informal operators willing to participate.

- Condition 3: Ability to manage relationships within the taxi industry. The processes leading up to the signing of a negotiated contract in Johannesburg opened up new fault lines in the taxi industry - between those included and those excluded from participation in the bus operating company. While incremental expansion of the BRT 
will see more and more taxi operators coming into the fold, the question is what happens at the boundary. BRT, with its expensive infrastructure and dependence on high passenger volumes, is not necessarily an appropriate solution in lower density areas, or along the semi-urban city margins, or in smaller towns and rural areas. A range of enhanced bus solutions are needed, not all of which are BRT. The question is how to sustain the transformation of the taxi industry - how to manage conflict between the included and the excluded - without the supporting logic of BRT. The possibility is there that current successes might be creating expectations that are difficult to meet.

\section{Conclusions: Lessons learnt on the role of Bus Rapid Transit in formalisation}

Perhaps the most important lesson the minibus-taxi experience in South Africa teaches is that transformation of an informal public transport industry into a formal industry, operating within the quality frameworks required by government, is not likely to be achievable via a heavy-handed, top-down regulatory approach. There is a distinct internal logic to operating informally, including relatively low entry barriers, the reduction of labour and operating costs, and the ready availability of a captive market. Informal operators historically saw no benefit in formalisation, as it promised access neither to new markets, nor to cost saving technologies, and therefore successfully resisted government's attempts at formalisation. In addition, in the South African case, the taxi industry was endowed with a certain amount of popular support and political credentials, born out of their history as resisters of Apartheid racial policies.

Yet, it seems that Bus Rapid Transit, in the way it is envisaged locally, is able to provide a structured mechanism through which (some) informal public transport operators can escape from the logic of informality. This makes BRT a potentially strong instrument in achieving government's strategic goals for public transport. An analysis of the characteristics of BRT and especially of its potential for helping to move a mature, technologically stagnant minibustaxi industry onto a new growth path - suggests that its transformational success rests on three key capabilities:

- The ability to drive down operating costs by capturing new scale economies via the use of larger vehicles, higher speeds, better vehicle utilisation, and more efficient labour practices. Efficiency needs to grow sufficiently to reduce, over time, subsidy needs while still ensuring that BRT participation remains financially attractive to informal operators.

- The ability to expand taxi operators' markets significantly beyond their traditional enclaves of captive users, which seem to be efficiently and fully exploited, to include current and future car users. Expanding markets are critical to providing attractive opportunities to an increasing number of informal operators.

- The ability of government authorities to secure an ongoing commitment from former taxi operators to abide by formal contracting and conflict resolution procedures, especially on the margins of the public transport market where BRT systems are less 
attractive and the premium payable to transform informal operators may be simply unaffordable.

In conclusion, while BRT in general offers significant promise for underpinning the formalisation and transformation of informal public transport operators, the jury is still out on the question of whether Bus Rapid Transit in South Africa will continue to do so in a sustainable and comprehensive manner.

\section{Acknowledgments}

Thanks to Roger Gorham (The World Bank), Roger Behrens (University of Cape Town), Paul Browning (consultant), and an anonymous reviewer for providing useful inputs on earlier drafts of this paper.

\section{References}

Ahmed, Y., 2004. Transformation of Public Transport operations from informal to formal services: An Examination of initiatives by the Western Cape Provincial Department of Transport to transform the minibus-taxi industry. Proceedings: CODATU 6 Urban Transport Conference. (http://www.codatu.org/francais/publications/actes/conferences/codatu11/ Papers/ahmed.pdf).

Barret, J., 2003. Organizing in the Informal Economy: A Case Study of the Minibus Taxi Industry in South Africa. Geneva, International Labour Office.

Barter, P., 2008. Public planning with business delivery of excellent urban public transport. National University of Singapore (unpublished paper).

Boudreaux, K., 2006. Taxing Alternatives: Poverty Alleviation and the South African Taxi/Minibus Industry. Mercatus Policy Series. George Mason University.

Browning, P., 2001. Wealth on Wheels? The minibus-taxi, economic empowerment and the new passenger transport policy. Proceedings: $20^{\text {th }}$ Southern African Transport Conference, Pretoria, 16 - 20 July 2001.

City of Johannesburg (COJ), 2007. Taxi industry signs on for Rea Vaya. 24 October 2007. (www.joburg.org.za/2007/oct/oct24 brt.stm)

City of Johannesburg (COJ), 2009. So far, so good for Rea Vaya. 9 October 2009. (www.joburg.org.za)

Cohen, T., 2009. MONDAY COMMENT: Will Rea Vaya take the high or low road? Business Day. 27 July 2009.

Department of Transport (DOT), 2003. Technical Report: National Household Travel Survey. Pretoria.

Department of Transport (DOT), 2006. Taxi Recapitalisation Programme. Press release. Pretoria (www.transport.gov.za/comm-centre/pr/2006/pr0410.html)

Department of Transport (DOT), 2007. Public Transport Strategy. Pretoria.

Development Bank of Southern Africa (DBSA), 2006. Report on Trends in Passenger Transport in the Republic of South Africa. Midrand. 
Dibetle, M., 2009. War of words escalates between taxis and city. Mail and Guardian, 29 August 2009. Johannesburg.

Dugard, J., 2001. From low intensity war to Mafia war: Taxi violence in South Africa (19872000). Violence and Transition Series. Centre for the Study of Violence and Reconciliation, Johannesburg (www.wits.ac.za/csvr/papers/papvtp4.html).

Finn, B., Arthur, B.A., Gyamera, S., 2009. New Regulatory Framework for Urban Passenger Transport In Ghanaian Cities. 11th Conference on competition and ownership in land passenger transport, Delft University of Technology (The Netherlands), 20-25 September 2009

Fourie, L.J., 2003. Rethinking the formalisation of the minibus-taxi industry in South Africa. Master's thesis, University of Pretoria. Pretoria.

Garrison, W.L., Levinson, D.M., 2006. The Transportation Experience: Policy, Planning, and Deployment. New York: Oxford University Press.

Gilbert, A., 2008. Bus Rapid Transit: Is Transmilenio a miracle cure? Transport Reviews, 28:4, pp. 439-467.

Grübler, A., 1990. The Rise and Fall of Infrastructures: Dynamics of Evolution and Technological Change in Transportation. Heidelberg: Physica-Verlag.

Gwilliam, K., 2006. International Experiences with Low Capacity Vehicles in Mass Transit Systems. Unpublished paper.

Hidalgo, D., 2009. Citywide Transit Integration in a Large City: The Case of the Interligado System, São Paulo, Brazil. Presented at Annual Meeting of Transportation Research Board, Washington, D.C.

Hook, W., 2005. Institutional and Regulatory Options for Bus Rapid Transit in Developing Countries: Lessons from International Experience. Presented at Annual Meeting of Transportation Research Board, Washington, D.C.

Khosa, M., 1991. Routes, Ranks and Rebels: Feuding in the Taxi Revolution, Journal of Southern African Studies. 18:1, p. 235.

McCaul, C., 1990. No easy ride: The rise and future of the Black taxi industry. Institute of Race Relations, Johannesburg.

McCaul, C., Ntuli, S., 2011. Negotiating the deal to enable the first Rea Vaya Bus Operating Company: Agreements, Experience and Lessons. Proceedings: $30^{\text {th }}$ Southern African Transport Conference, Pretoria, South Africa.

Motshwane, E., 2011. Personal communication.

Oosthuizen, S., Mhlambi, M., 2002. The road to empowerment of the minibus-taxi industry is full of pitfalls. Proceedings of $21^{\text {st }}$ Annual Southern African Transport Conference, Pretoria. 15 - 19 July 2002.

Perkins, P., Fedderke, J., Luiz, J., 2005. An Analysis of Economic Infrastructure Investment in South Africa", South African Journal of Economics, 73:2 June 2005.

Portes, A., Castells, M., Benton, L (Eds), 1989. The Informal Economy: Studies in Advanced and Less Developed Countries. Baltimore: The Johns Hopkins University Press.

Prinsloo, L., 2011. R3bn Rustenburg rapid transport project launched. Engineering News. 22 July 2011. (www.engineeringnews.co.za). 
RSA, 2012. Minister of Transport Sibusiso Ndebele: The Infrastructure Development Cluster media briefing, Cape Town, 28 February 2012. (http://www.info.gov.za)

Schalekamp, H., Mfinanga, D., Wilkinson, P., Behrens, R., 2009. An international review of paratransit regulation and integration experiences: Lessons for public transport system rationalisation and improvement in African cities. 11th Conference on Competition and Ownership in Land Passenger Transport, Delft University of Technology (The Netherlands). 20-25 September 2009.

Walters, J., 2008. Overview of public transport policy developments in South Africa. Research in Transportation Economics, No 22, 2008, pp. 98-108. 